\title{
The partnership of governments for sustainable development
}

\author{
Galiya Dauliyeva ${ }^{1}$, Aruzhan Yeraliyeva $^{1}$, Gulnara Sadykhanova ${ }^{1, *}$, Laila Bimendiyeva ${ }^{1}$ \\ ${ }^{1}$ Al-Farabi Kazakh National University, Department of Management, al-Farabi Ave. 71, 050040 \\ Almaty, Republic of Kazakhstan
}

\begin{abstract}
Partnership of government and business is an important tool to drive change to more responsible and sustainable development. This type of partnership can help to solve some problems as market failures, governance gaps and trust deficits that prevent the acceleration of business engagement in sustainable development. They can also become a base for coordinating different actions of numerous actors and for building mutually reinforcing linkages between differentspheres for sustainable development.The article offers diverse ways to businesses and governmentfor building better partnership: realizing the benefits of partnership of government and business in supporting sustainable development; raising the level of investment and innovation in sustainable development; reaching transformation of this kind of partnership to work better for people and the environment; and building mutual trust and responsibility between government and business.
\end{abstract}

\section{Introduction}

The Sustainable Development is an action plan for reaching social and environmental sustainability in the world. Over the past decades, sustainable development has often been compartmentalized as an environmental issue. According to an even more limited conception sustainable development is development as purely economic growth, referring to the wealth of developed countries, which jeopardizes natural resources, biodiversity and natural environments. In the last two decades it became clear that economic and environmental issues cannot be separated from social concerns, but the integration of these areas is not easy and needs a new development paradigm [1].

Good governance was identified at the World Summit on Sustainable Development as a critical factor for ensuring successful sustainable development [2]. At the same time, environmental issues have gradually become regular aspects of modern business management. With some success and considerable effort by the business and government, local and regional environmental conditions are steadily improving in most countries [3].

The primary basis of effective partnerships is their ability to lead various resources in method that can together reach more: more influence, better sustainability, growing importance for everyone. The significance of partnership has been acknowledged totally by the UN, by business and by all core institutions in international development. The 2030

\footnotetext{
${ }^{*}$ Corresponding author: gulnara.sa@gmail.com
} 
Sustainable Development Goals - the plan for worldwide development - shows significant growth in thinking, exactly recognizing the connectedness of thriving business and a healthful environment. They mention all spheres as core development actors and need an unexampled level of interaction and collaboration between businesses and government for their achievement.

The Goals require co-ordination and administration across sectors and societies presenting those charged with its implementation unprecedented governance tasks. It is heady stuff full of universal ambition, but its implementation will depend on states in very different contexts, tackling these issues in their own particular ways [4].

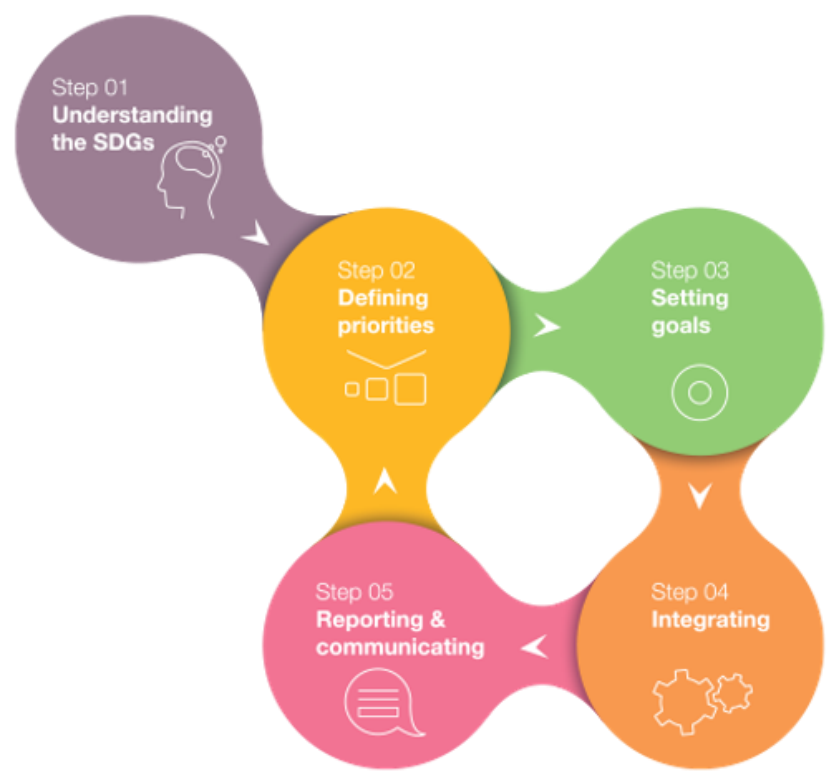

Fig. 1. Sustainable Development Goals (SDGs) steps [5].

KPMG's survey shows that the Sustainable Development Goals have resonated strongly with businesses worldwide in less than two years since their launch. Around four in ten corporate responsibility reports from both N100 and G250 companies make a connection between the company's corporate responsibility activities and the Sustainable Development Goals [6].

Strategic unions between business and government are an increasing characteristic of both developed and developing economies. Such partnership is needful because it is obvious that no one area in society can solve the difficulties of sustainable development on its own. Partnerships for sustainable development are comparatively new phenomena. Unlike contract relationships or private-public partnerships, they seek not to switch responsibility and risk from one party to another, but to share risks, pool resources and bring mutual benefits. In the context of performing sustainable development and corporate social responsibility goals in poor countries, no company can be all things to all stakeholders. Its success in this area will depend on a business model that exploits its core competencies while partnering with those who bring the necessary complementarities to form more complete solutions. Partnerships for sustainable development are thus no different in principle from common business-tobusiness strategic unions [7].

First and primarily through the manner in which they conduct their own business activities and the leverage they have across their value chains. Every company can contribute positively 
to sustainable development by reducing the negative impacts on people's human rights and on the environment associated with its business - including across its value chain. Far from viewing respect for human rights and protection of the environment as merely a matter of compliance, risk management and 'do no harm', these commitments can be powerfully affirmative, transformative and even disruptive of traditional practices.

Second, some companies will also be able to contribute to the sustainable development by implementing new and innovative products, services, technologies and ways of doing business that can improvepeople's lives, and to improve the environment and fighting climate change. They should do so wherever they can, but never as a substitute for respecting human rights and protecting the environment. Despite the potential of companies to make a meaningful contribution to the sustainable development in these two ways, their impact is often constrained by a combination of governance gaps, market failures and high levels of mistrust between the private sector and other stakeholders. Although by no means a panacea, partnership and collective action can help to get over some of these problems.

\section{Results}

Issues of sustainable development lie in the environmental, economic, social, and political spheres. Some of them can be solved within national borders, while others (e.g. communicable diseases, climate change) permeate across countries and need resolution through cooperation of government and business worldwide [8].

The sustainable development is more than only a desirable framework for governments. They are an action plan for business potential. There are a lot of irresistible motives for businesses to pursue social influence and practice the sustainable development. Behind the necessity to note society's call for clarity and better accountability, mixing purpose with profit can produceaexceptional competitive excellence well-suited to penetrating consumers and investors.

One of the drivers of financial importance enforce companies to do both social influence and sustainable development alignment part of their basic business for generating new revenue by making new opportunities to market derivation and progress. In global economy, the appearance of a new world's middle class, dramatic growth in consumer preferences to 'responsible' goods and humble innovation are making new markets ready for growth.

The next reason for businesses to engage with the sustainable development is desire to enroll and retain talent by optimizing work-force. Behind the generation of new revenue and growth, variety and inclusion are highly connected to improvements in company performance and are making a competition for talents. Businesses nowadaysare in competition globally for progressively scarce technical and professional abilities. Corporate citizenship is appearing as anvaluable criterion in the talent market. This has driven to more socially responsible companies getting an advantage in engaging and retaining top employees.Sustainable developmentas well impacts on growing supply chain resilience by strengthening supply chain sustainability and operational effectiveness. Optimizing supply chains for resilience can decrease transaction costs and raise operational efficiency. Behind revenue increases by growth and new market potentials, engagement in social influence can help to control costs and optimize efficiency. For example, supply chain sustainability is highly understood to be a basicdriver of business value while making important contributions to companies' reputations and brands. In the rising retailer-driven supply chain environment, suppliers are seeking opportunities to show themselves by not only reducing costs, but by introducing social and environmental decisions. The sustainable development in business has also enhanced investor interest by raising attraction to a greater range of investors. The sustainable development isgoing to be shown as the framework against which many sustainable investments will be evaluated for social and environmental influence. Companies 
making social impact as a part of their basic business strategies are seeing growing access to financing in different formats - from philanthropic grants and influence investments to partial credit guarantees and pay for performance.

Sustainable development in business ensure license to act by directing regulatory compliance and controlling risks.Making asustainable development givescompanies more options when controlling risks associated with their license to act. An accent on transparency and accountability composed with environmental pressures keepsto moveinto growing regulatory study. Actually, policy and regulatory risk has increased significantly in emerging markets since the 1980s. Companies that clearly recognize the dynamism of the environment in which they act can introduce suitable strategies to address it [9]. Strong community bonds, goodwill from governments and respect from locals can decrease political and regulatory risks. Governments are increasingly giving both positive and negative stimulus to maintain domestic production and consumption, which can drive an inclusive business development. A rising number of countries globally are supporting inclusive businesses through a different policy tools. These strivings are accelerated by the governments' wish to engage the private sector in order to speed up the pace of addressing poverty and other social and environmental problems.

\subsection{Partnership between government and business in achieving sustainable development}

To achieve sustainable development it will be necessary that business activities, particularly those of big companies, totally enroot responsible business practices and performance standards. These include:

- respecting human rights of people whose rights are touched in relation with a company's services and products;

- zero tolerance to corruption and clear payment of taxes;

- environmental, social and governance standard models.

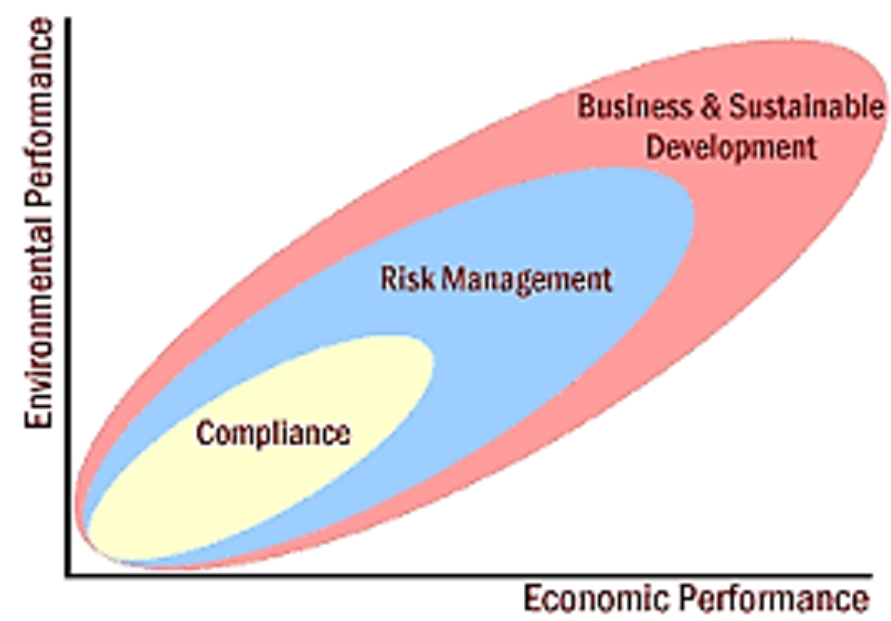

Fig. 2. Business and Sustainable Development [10].

The realization of responsible business practices and performance standards is not only a risk management strategy that can support companies in earning legal and social 'license to operate'. They can also support spreading international standards and best practices to countries where local governance models or institutions are weak. And they can unleash and 
build the facilities of assailable groups of people who either work in or are touched by worldwide value chains in ways that exactlyget better lives and enhance achievement of the sustainable development.

Except implementing responsible business practices, companies can strengthen the contribution of their existing practices to sustainable development in a differentother fields. This contains focusing on local job creation, training and human capital development, improvements in productiveness and resource efficiency, improving access and affordability of essential goods and services, implementing transparent and more inclusive technologies, which support physical infrastructure development, and enhancing institutions. The organization Shift has offered anuncomplicated framework as an instrument for helping all companies to estimate and control their impacts on people and planet. It proposes a complex approach, ensuring that the various activities through which a company affects sustainable development are aligned to increase positive outcomes for people [11].

Shortly, the development influence of existing private investment and business activities can be significantly improved if companies take a complex approach to respecting human rights and finding the risks and opportunitiesconnected to sustainable development most relevant to them and their stakeholders; and then introduce transparent policies, aims and strategies to decrease shared risks and maximize shared opportunities.

The potential is large, yet even the companies that are heading on sustainable development face stronglimitations in their efforts to implement transformational change. These include challenges in achieving scale through their own operations on a voluntary base, particularly if there is limited pressure from stakeholders to do like this. Connected to this is the challenge of being able to compete on a level-playing area with sustainability laggards when investors, consumers and regulators do not place significant contribution on superior sustainability performance and do not totally account for or penalize negative social and environmental external factors.

Partnership between government and business can help to address these difficulties by introducing a level playing area for responsible business standards on an industry-wide base or among specific countries and value chains. They can become a tool for targeted joint action with clear aims to direct shared challenges, and to make better performance along value chains. They can also help to guaranteebetter corporate transparency and accountability, both on an individual and collective basis.

\subsection{The role of partnerships in increasing the level investment and innovation for sustainable development}

In order to attain the 2030 Agenda it will be needful to go behind improving the influence of existing private sector activities. There is a serious need to mobilize, catalyze and channel substantially more funding for the SDGs as well as various types and sources of funding. There is a necessity to shift from billions to trillions in resource flows [12].

The local and international public finance will stay essential, but they are not enough. It will be imperative to lift the level of private finance and investment in the SDGs in all countries, especially low- and middleincome countries with rising populations. This includes both portfolio investment and direct investment, both domestic and foreign [13]. It also contains mobilizing private sector expertise and scaling capabilities, ranging from science, operational capacities, technological and research skills to the innovation, implementation of business. Partnerships aresignificantinstrument for leveraging various public and private financial resources, expertise and capabilities. They make it real to share the risks and costs of introducing and scaling new products, services, technologies and business models that have the potential to address specific SDGs but do not initially meet corporate hurdle rates on a fully commercial base. They can also help to improve the risk profile and returns of 
more traditional, long-term investment in spheres such infrastructure or in high-risk locations and weak states. As such, they can unlock private capital and capabilities to invest in spheres or locations where sustainable development needs are most, but where a combination of market insufficiencies and governance gaps impede commercial rates of return, either initially at the start-up phase or on a longer-term base [14].

\subsection{Achieving systemic transformation of markets}

Increasing the sustainability performance of specific companies and business activities and improving private investment in specific projects and spheres are needful, but not enough. In addition to introducing responsible practices and more inclusive and sustainable ways at the level of individual companies and projects, there is also a need to attainwider and more systemic market transformation in many spheres. No company can do this on its own. Nor can any government. Systemic change needs numerous diverse interventions at various levels and from different actors. In addition, it needs intermediary organizations or partnership platforms that can help to support, align and coordinate these different efforts [15]. Transformation will be especially important in core value chains and markets such as forestry, food and mineral goods, energy, health, education, labor, financial services and housing. It will be significant for respecting human rights, tackling inequality, increasing employability, creating productive jobs, including low-income producers, workers and consumers, scaling technological breakthroughs, and addressing systemic and interconnected environmental and social challenges. The major corporations that are active players in core value chains and markets have especially vital leadership role. In many cases, a comparatively small number of 50 to several hundred influential companies can deliver the critical mass that is needed to catalyze change and drive it through their value chains and business ecosystems [16].

If we can get a critical number of companies to usereliable production standards, we can lead markets of goods to a tipping point where sustainability becomes normal. Same arguments can be made for other key value chains and markets. Industry-wide or multistakeholder platforms that shift from transactional partnerships to more transformative or systemic models can play a core role. They can allow collective advocacy for the policy reforms that are often needed for such change. They can facilitate improved data collection, analysis and benchmarking to drive industrywide improvements in performance and accountability. They can align and coordinate the diverse interventions of participating institutions. Moreover, they can help to improve the enabling environment for reaching shared business value and development results more broadly, including for small and medium enterprises.

\subsection{Building mutual trust, accountability and a new social contract between business, government and civil society}

Trust in both business and government remains at alarmingly low levels. Political and business leaders are facing growing public discontent and a backlash against globalization and large corporations, as citizens struggle to deal with rising inequality, an inability to benefit from digital and other technology breakthroughs, and job insecurity and uncertainty. In short, at a time in the world's history when the resources and capabilities of private enterprise are needed more than ever before, business leaders are facing a large public trust deficit. While by no means a panacea, partnerships and coalitions that enable government officials and business leaders to engage and consult more effectively with each other and with citizens are one tool that can help to address this challenge [17]. They can help to jointly identify key priorities and concerns, and co-create a shared vision and agenda for change 
among diverse and often dissenting individuals and organizations. If effective, they can help to build mutual respect and trust and strengthen the social contract between business, government and society. In summary, effective partnerships and coalitions can help to overcome market failures, governance gaps and trust deficits that impede both business progress and more inclusive and sustainable development. There is an increasingly strong business case for companies in all spheres and countries to get more engaged in such collaborative efforts. This business case includes their potential to improve the broader investment climate or enabling environment for doing business, enhance enterprise risk management, help companies to harness new business opportunities and markets, and increase the level of employee and stakeholder loyalty and engagement.

\section{Conclusion}

Corporate responsibility and sustainable development are two concepts that may be able to reconcile many of the big challenges facing the world; challenges such as tensions between respect for the natural environment, social justice, and economic development; the long view versus short-term imperatives and the competing priorities between developed and developing economies [18].

There is an increasing need to clearly understand what works and what does not in building effective partnerships at various levels. A lot of studies have been undertaken to evaluateand learn from individual partnerships, but there is currently no general database to review and compare these various studies and no fully agreed framework of analysis [19].

Very little comparative analysis has been undertaken of larger datasets of partnerships, whether within particular industry spheres or to address particular development goals and sustainability issues.As a result, it is difficult to draw empirical conclusions on the overall contribution, reach and impact of existing partnership between business and government for sustainable development.

Many studies offer encouraging feedback on the potential of partnerships. At the same time, they highlight some common critiques and challenges. These include:

- Leadership, governance and accountability: Many critics point to concerns about governance and funding ofbusinesses, which is not sufficiently transparent or accountable in terms of measuring, evaluating and reporting on performance and progress. Linked to this are concerns about representation of beneficiaries in governance structures, whether these are government officials that are recipients of a global partnership or lowincome communities and citizens. A related issue is the challenge of dealing with power dynamics and making sure that appropriate grievance mechanisms and conflict resolution approaches are in place if needed.

- Operational efficiency and effectiveness: A number of studies have concluded that the high transaction costs and specific types of skill sets needed to build effective publicprivate partnerships, especially complex multi-stakeholder initiative make them more costly and time consuming and ultimately less efficient and effective than governments or companies simply working on their own. Studies also point to the fact that many initiatives fail to deliver on the goals they set at the beginning of the partnership. These and other assessments of the operational, governance, and accountability challenges of multi-stakeholder partnerships point to the ongoing need to improve evaluation and transparency in assessing their development outcomes relative to their transaction costs, business benefits and political influence. These critiques should not, however, detract from the untapped potential of building partnerships between business and other spheres in order to reach more inclusive, responsible and sustainable growth.

In conclusion, partnerships are a tool. They are a means to an end, not an end in themselves. In the majority of cases, that 'end' is to reach greater scale, greater legitimacy, 
greater systemic or transformational impact and/or greater sustainability than the participants would be able to reach on their own. They are driven by a shared recognition that many development problems are too complex and interdependent, and the financial, technical and managerial resources for tackling them are too scarce or too widely dispersed among different actors, not to search for new approaches that draw on the resources, skills and capacities of all spheres. Partnerships are by no means a panacea and are often costly and time consuming to build and sustain. Yet, they offer one of the best tools available for business to work with other spheres in delivering the sustainable development goals in a way that makes good business sense [20]. The business case for partnerships is increasingly clear in terms of spreading responsible standards and practices, identifying and mitigating shared risks, finding opportunities to create shared value, and contributing to a sound enabling environment. Above all, partnerships require outstanding individual leadership. Effective partnership building, especially across spheres, requires new mindsets and skill sets on the part of individuals and new capabilities and incentives on the part of institutions. It requires patience, persistence and a long-term commitment in an era of short attention spans, accelerating and disruptive change and short-term performance pressures on companies and governments alike. None of this is easy. Yet, it is essential work if we are to make progress at the scale and systemic impact that are required. The ability to galvanize and convene businesses to co-create effective partnerships for sustainable development has become one of the essential leadership imperatives for our Century.

\section{References}

1. O. F. Williams, T.\&F. Inc., Corporate social responsibility: The role of business in sustainable development, 6 (Routledge, 2013)

2. R. Callway, T.\&F. Inc., Governance for sustainable development: A foundation for the future, 26, 17-23 (Earthscan, 2013)

3. G. Keijzers, T.\&F. Inc., Business, government and sustainable development, 3, 35 (2004)

4. S. Dalby, S. Horton, R. Mahon, D. Thomaz, T.\&F. Inc., Achieving the sustainable development goals: Global governance challenges, 1, 3 (2017)

5. UN Global Compact https://sdgcompass.org/

6. KPMG, Currents of Change: The KPMG Survey of Corporate Responsibility Reporting, 14-15 (2015)

7. M. Warner, P.M., Partnerships for Sustainable Development: Do We Need Partnership Brokers? 8-9 (2003)

8. A. Estevadeordal, L.W. Goodman, T.\&F. Inc., 21st century cooperation: Regional public goods, global governance, and sustainable development, 4 (2017)

9. L. Berlie, P.M., Alliances for Sustainable Development: Business and NGO Partnerships, 7 (2009)

10. International Institute for Sustainable Development https://www.iisd.org/business/sd_journey.aspx

11. J. Nelson, IBLF Policy Paper, 4, 12 (2003)

12. Prepared jointly by the African Development Bank, the Asian Development Bank, the European Bank for Reconstruction and Development, the European Investment Bank, the Inter-American Development Bank, the International Monetary Fund and the World Bank, F.D., From Billions to Trillions: Transforming development finance, (2015)

13. B. Mukhamediyev, Z. Temerbulatova, International Journal of Energy Economics and Policy, 9(6), 45-50 (2019)

14. The United Nations

https://www.un.org/sustainabledevelopment/globalpartnerships/ 
15. J. Nelson, \& B. Jenkins, T.\&F. Inc., Tackling Global Challenges: Lessons in System Leadership from the World Economic Forum's New Vision for Agriculture Initiative, 5 (2016)

16. S. Kondybayeva, S. Abilday, B. Mukhamediyev, B. Baitanayeva, A. Abylay, Proceedings of the 31st International Business Information Management Association Conference, 4288- 4294 (2018)

17. The Sustainable Development Goals Fund (SDG Fund) https://www.sdgfund.org/howcan-you-partner-sdg-fund

18. L. Rayman-Bacchus, P. R. Walsh, T.\&F. Inc., Corporate responsibility and sustainable development: Exploring the nexus of private and public interests, 4 (2016)

19. Fiona Starr, T.\&F. Inc., Corporate responsibility for cultural heritage: Conservation, sustainable development, and corporate reputation, 9 (2013)

20. The United Nations (UN) https://sustainabledevelopment.un.org/partnership/?p=9691 